\title{
Hydrodynamic modelling of short-term dispersion in a macro-tidal sea, validation by high-resolution radionuclide tracer measurements
}

\author{
P. Bailly du Bois ${ }^{1}$, F. Dumas ${ }^{2}$ and L. Solier ${ }^{1}$ \\ ${ }^{1}$ Institut de Radioprotection et de Sûreté Nucléaire, Laboratoire de Radioécologie de \\ Cherbourg-Octeville (IRSN/DEI/SECRE/LRC), \\ rue Max Pol Fouchet, BP. 10, 50130 Cherbourg-Octeville, France \\ ${ }^{2}$ IFREMER/DEL Applications Opérationnelles,
} Centre de Brest, Z.I. de la Pointe du Diable, BP. 70, 29280 Plouzané, France

\begin{abstract}
This work aims to validate the dispersion parameters of hydrodynamic models for the short term (hour to week), and short distances (100 m - $30 \mathrm{~km}$ ), by using high precision and high frequency measurements of tritium obtained in the release plume. An instantaneous 2D hydrodynamic model has been developed with a mesh size of 110m and an area of 50x50 km. More than 7,000 samples have been collected and measured for tritium concentrations in 2002 and 2003. Currents and bathymetric measurements, as well as drifters observations complete these measurements. Results confirm the efficiency of the hydrodynamic model, main differences being attributable to bathymetry incertitudes. After calibration, the model gives accurate results during six hours following a release. The obtained field database represents an exceptional tool for hydrodynamic models validation in realistic conditions of releases, tide and wind, in an area where the current dynamic is particularly strong (more than $5 \mathrm{~m} / \mathrm{s}$ during high tides). The dispersion parameters obtained will be applied for other hydrodynamic models covering continental macro-tidal seas. Such models will be used to simulate soluble pollutants dispersion, with known uncertainties, in realistic chronic or accidental release conditions.
\end{abstract}

\section{INTRODUCTION}

Assessing the impact of polluting substances released into a marine environment, be it through normal or accidental conditions, is seemingly becoming a more and more acute requirement in European seas: a significant proportion of world trade passes through them and many industrial waste outfalls land up there. Hydrodynamic soluble substance dispersion models have been developed that reproduce instantaneous or residual tide currents with great variation in spatial extensions and calculation resolutions. However, these advection and dispersion models have generally no field data allowing them to be validated accurately in an environment close to a waste outfall for periods extending from one hour to one week and distances of 100 metres to $30 \mathrm{~km}$.

It has been possible to constrain the medium- and long-term dispersion models using in situ tracer measurements and to achieve a realistic representation of the water mass dynamics for one week up to several years [1], [2], [3]. Comparable data can be acquired to validate a near-field dispersion model. The objective of this work is to calibrate key parameters improving the simulation of soluble substances dispersion during the short term in any zone of the North-western European continental shelf, with known accuracy. 


\section{CHOICE OF STUDY ZONE}

Several criteria suggest the choice of the Cap de La Hague zone to validate a short-term dispersion model: - This zone has particularly intense tidal dynamics with currents exceeding $5 \mathrm{~m} / \mathrm{s}$; the topography is varied (numerous bays and capes, depths between 10 and 100 metres). A model working efficiently in such a complex zone can be considered reliable in European macro-tidal seas;

- Waste from the COGEMA La Hague spent nuclear fuel reprocessing plant released in the Raz Blanchard off Cap La Hague has been known accurately since 1982; it is the main source of artificial radionuclides in the Channel, higher by two orders of magnitude than other sources of tritium. These are outstanding tracers for studying dispersion in marine environments;

- the released tritium, strictly conservative in seawater in the form of HTO, is easy to sample and measure (liquid scintillation measurement). A large number of measurements can be taken in situ;

- The labelling induced by the waste from the La Hague plant is clear: concentrations measured in the outfall plume vary from 100 to 3,000 Bq/l for every tritiated release, the concentrations induced along the Cap de La Hague coasts are approximately $10 \mathrm{~Bq} / \mathrm{l}$, they are still $4 \mathrm{~Bq} / \mathrm{l}$ in the Straits of Dover. These values should be compared with the "background" of water entering the Channel from the West which is around $0.15 \mathrm{~Bq} / \mathrm{l}$;

- Numerous data have been obtained in the past: labelling using rhodamine in 1962 and 1963; monitoring drifting buoys; measurements of soluble radiotracers obtained by IRSN since 1984 .

\section{HYDRODYNAMIC MODEL}

Table 1. Main characteristics of models generating limit conditions of the La Hague near-field model (DISPRO).

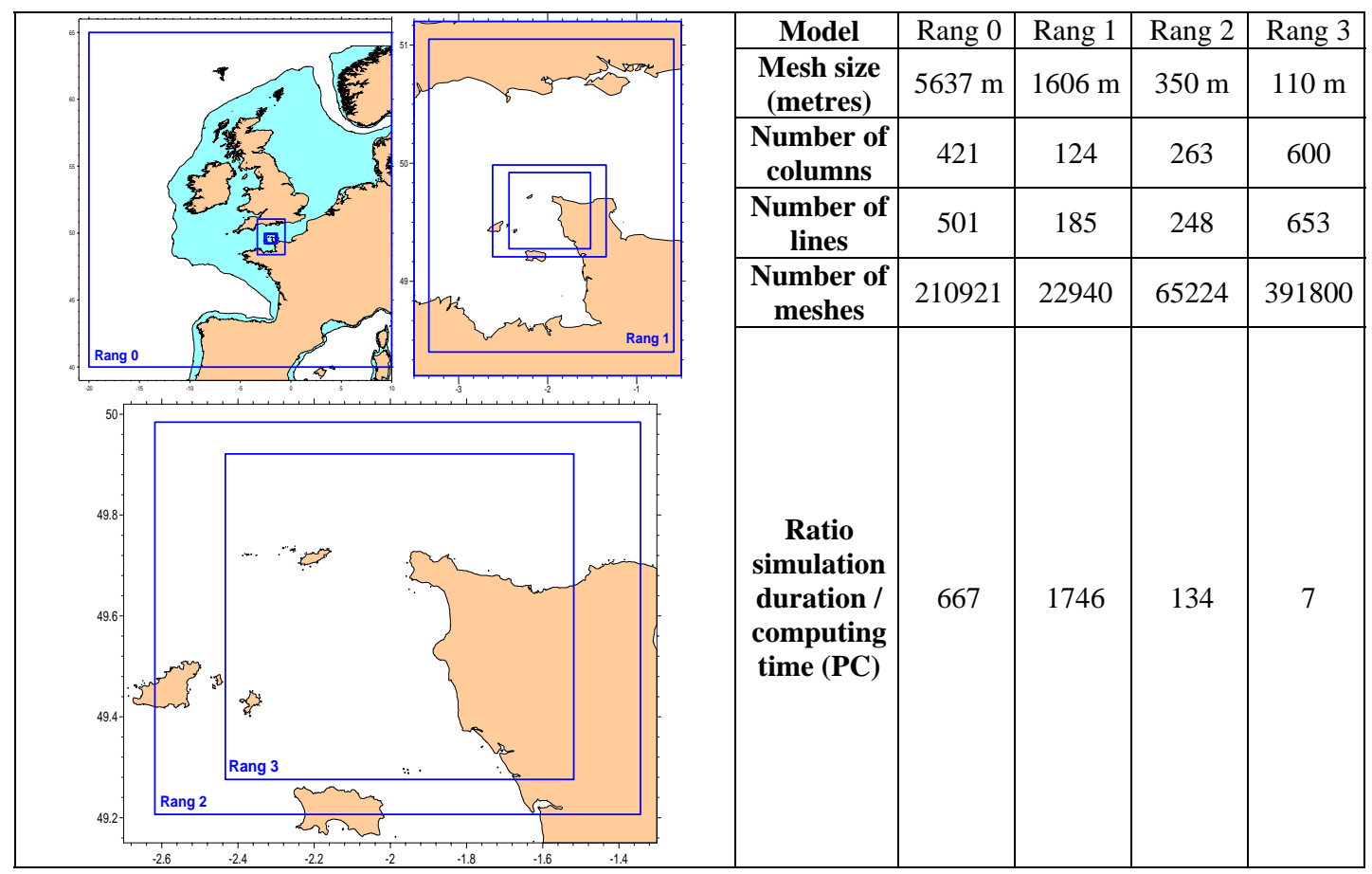

A 2D numerical model solving the Saint Venant equations (Navier-Stokes equations integrated into the vertical) is the tool used to calculate the characteristics of the tide currents throughout the area: the discretisation of the calculation field is based on finite differences on a $\mathrm{C}$ grid under the Arakawa classification. The numerical scheme used is derived from the ADI method (Alternate Directive Integration), taking into account uncovered bank processing. 
The model is steered to open limits on the open sea by the variation in the free surface level linked to the progress of the tidal wave and over the entire area by atmospheric forcing (wind, pressure). There is no speed control; the positioning of the free surface is calculated using models of larger outfalls, which characteristics as presented in Table 1. They work under a system of spherical coordinates, with the limit conditions of the largest model fixed using the Schwiderski harmonic component atlas (1983). The limits of the largest model have been pushed beyond the continental margin (at more than an external deformation radius from Rossby) so that the wind only very slightly affects the variations in the free surface. Closed limit conditions (land) are simply nil flow conditions. The surface limit conditions relate to the frictional forces of the wind on the sea. The bottom limit conditions relate to the frictional forces of the water movement compared with the seabed.

\section{ACQUIRED DATA}

\subsection{Tritium measurements during sea campaigns}

7,200 dissolved tritium measurements were obtained from seawater samples taken on board the INSU/CNRS ship "Côtes de la Manche” during five campaigns in 2002 and 2003. The sampling strategy was adapted to the actual times of releases from the COGEMA plant during each campaign, accounting real dispersion conditions.

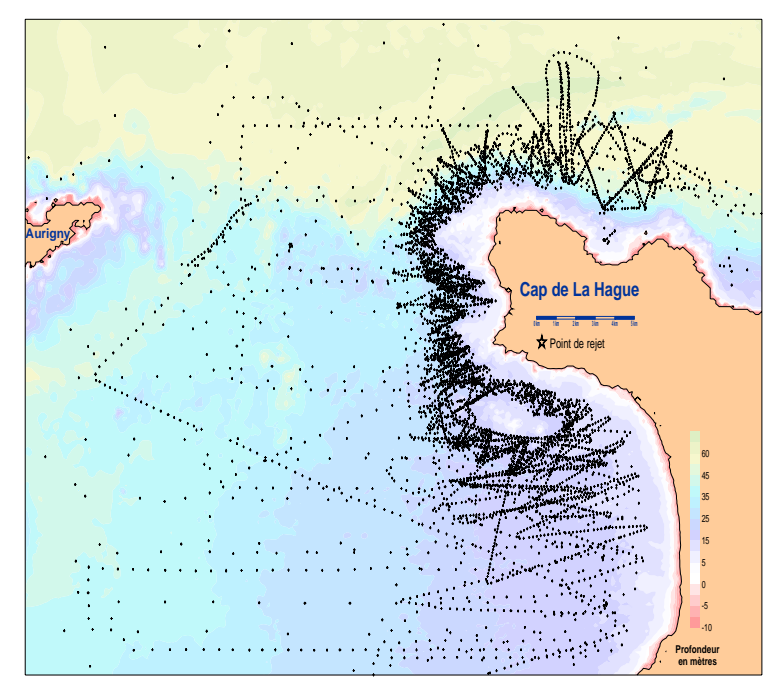

Figure 1. Localisation of samples taken during the DISPRO campaigns.

\subsection{Current and water depth measurements}

During the sea campaigns, current profiles were obtained using an Acoustic Doppler Current Profiler (ADCP) immersed in hydrodynamically-characteristic zones. This equipment and the boat's echo sounder were used to acquire water depth recordings during one or several tidal cycles.

\subsection{Float monitoring}

Observations from drifting buoys monitoring carried out by the French Navy in 1962 and 1963 have been digitised. This lagrangian buoy represents average currents of the topmost 15 metres water column. 


\subsection{Meteorological data}

The analysis data from the ALADIN and ECMWF meteorological models were acquired from Météo-France. The forcing of the wind-related model is currently being calibrated.

\subsection{Bathymetric readings}

Special attention was given to collecting bathymetric data and their insertion into the model [4]. In addition, 47,000 bathymetric readings were taken during the DISPRO campaigns; they were corrected for tide by the French hydrographic department (SHOM).

\section{MODIFIED PARAMETERS}

The model produced good results before being calibrated with the field data. A comparison with these data made it possible to improve the representativity of the simulations significantly by modifying some parameters.

The model could be time constrained to give or take 15 minutes based on when the tide turned by using the current and water depth measurements (Figure 2).

With the initial parameters, the model under-estimated slightly the speeds compared with the observations, the Strikler friction coefficient was modified and standardised for all the models (rang 0-

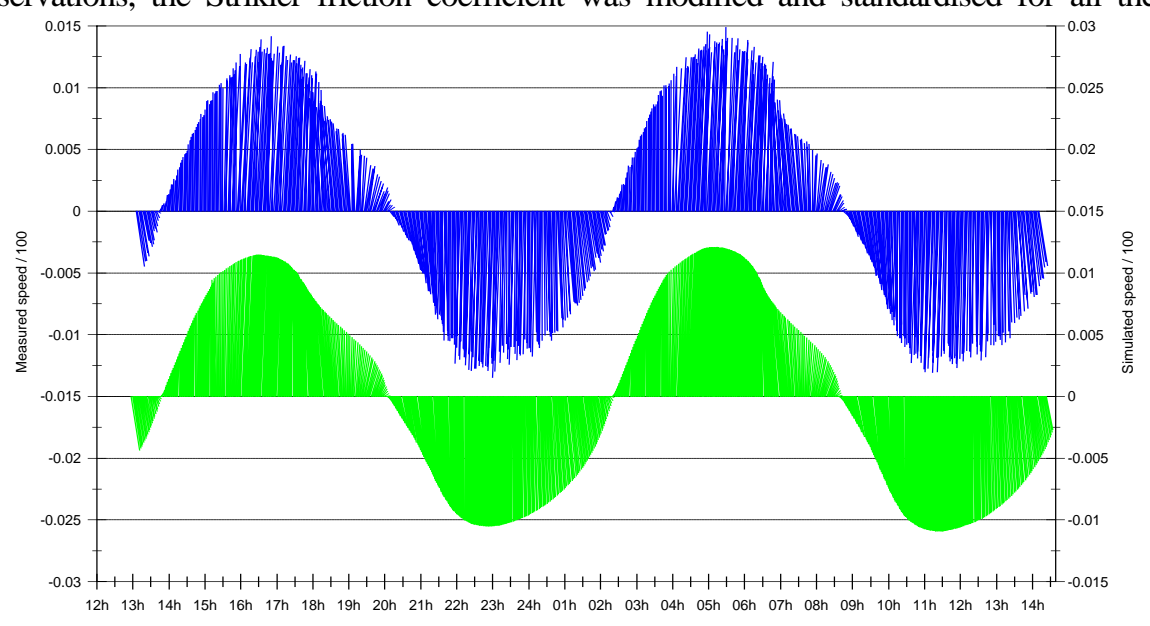

3).

Figure 2. Average currents measured (top) and calculated (bottom) by the model in the Anse de Vauville.

\section{RESULTS}

\subsection{Comparison between measured and calculated speeds}

The discrepancies between the measured and simulated speeds are below $10 \%$ in zones with uniform hydrodynamics (Figure 2). These discrepancies can increase in significance near the coasts, which is explained by the lesser understanding of the bathymetry in these zones. The model clearly reproduces the float trajectories observed in 1962 and 1963 (Figure 3). The differences observed to the north of Cap de la Hague can logically be attributed to variations in depth of $30 \mathrm{~m}$ to $90 \mathrm{~m}$ : the trajectories of floats sea anchored at 15 metres cannot represent the average water flow calculated by the model. 


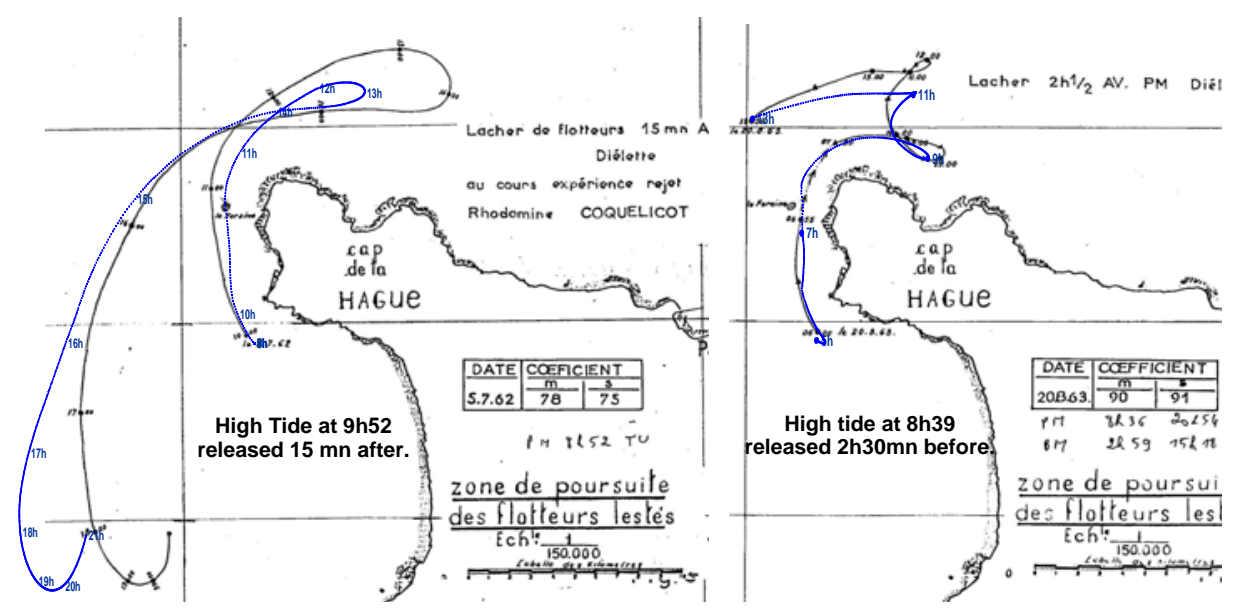

Figure 3. Drifting buoys trajectories observed in 1962 and 1963 (black lines) and simulated (blue lines).

\subsection{Comparison between measured and calculated tritium concentrations}

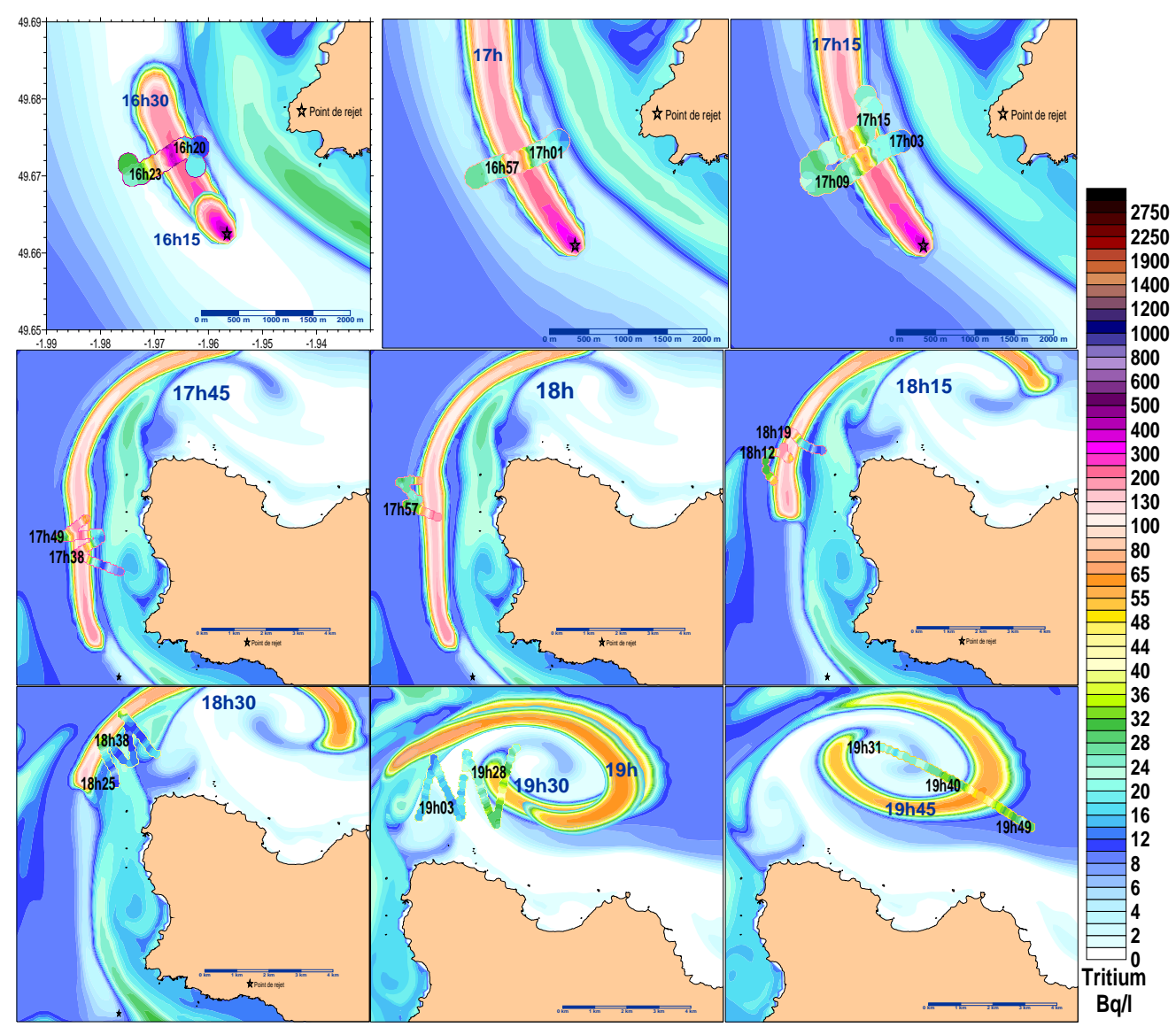

Figure 4. Comparison between simulated (background, times in blue) and measured (series of coloured dots, times in black) concentrations between 4 p.m. and 8 p.m. on 12 June 2003. 
Nine releases have been monitored under different hydrodynamic conditions (light to strong wind, current flowing southwards or northwards at the time of release). Between 500 and 1,000 dissolved tritium measurements were obtained for each release. The model simulates the dispersion accurately during the six hours following the start of the release. The results are less accurate when the plume is carried southwards, which is explained by a lesser understanding of the bathymetry on the rocky outcrop located south of the outfall. Figure 4 illustrates an example of the model's ability to reproduce measured plumes.

\section{CONCLUSION}

The acquired data forms a unique basis for refining model dispersion parameters for actual conditions of release, tide and wind, in a zone where the current dynamics are particularly active (Raz Blanchard off Cap de la Hague).

At the current state of the project, the model can be considered to represent reliably dispersion during the six hours following a release. Beyond this the wind has significant influence. Setting the parameters for this forcing will be dealt with in future studies. The objective is to obtain similar accuracy during the days and weeks following a release. For longer dispersion simulations, other tools are used to represent dispersion during several years at the scale of the Channel or the North Sea [3].

The results obtained during the DISPRO campaigns will be generalised for the entire Channel using coarser resolution models. The dispersion parameters established with a model of 100 metres resolution will be tested and adjusted with less accurate models. The ultimate aim is for hydrodynamic models with known uncertainties, to simulate the dispersion of natural or man-induced soluble substances with reasonable calculation times. The models will be applied to reproduce the dispersion of chronic or accidental releases on northwest European continental shelf.

\section{Acknowledgements}

We should like in particular to thank the crews of the INSU/CNRS ship "Côtes de la Manche” who allowed us to take samples in difficult conditions; the IRSN Laboratory of Radioactivity Measurement in the Environment (LMRE) and the Groupe d'Etudes Atomiques (GEA) from the French Navy, that made it possible to measure the tritium; and the team from UMR 6143 Continental and Coastal Morphodynamics at the University of Rouen, for the current and water-column density measurements.

\section{References}

[1] M. Breton, J.C. Salomon, Journal of Marine Systems 6, 5-6 (1995), 495-514.

[2] P. Bailly du Bois, P. Guéguéniat, Continental Shelf Research 19 (1999), 1977-2002.

[3] P. Bailly du Bois, Rapport IRSN/DPRE/SERNAT/ 2003-04 (2003), 188 p.

[4] P. Bailly du Bois, Rapport IRSN/DPRE/SERNAT/ 2004-04 (2004), 17 p. 